\title{
Descrição da fêmea de Paracentronodus nevesi Barreira \& Sakakibara (Hemiptera, Membracidae) ${ }^{1}$
}

\author{
Rembrandt R. A. D. Rohthéa ${ }^{3,4}$ \& Antonio José Creão-Duarte ${ }^{2,3}$
}

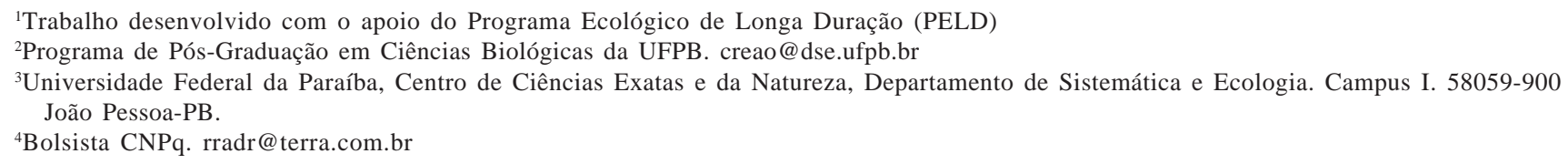

\begin{abstract}
Description of the female of Paracentronodos nevesi Barreira \& Sakakibara (Hemiptera, Membracidae). A female specimen of Paracentronodos nevesi Barreira \& Sakakibara, 2001 was collected in a semi-arid region (Caatinga) of the State of Paraíba, Brazil, at the municipality of São José dos Cordeiros. Since only the male was known, the specimen is described and illustrated.
\end{abstract}

KEYWORDS. Caatinga; Centronodinae; Homoptera; taxonomy.

RESUMO. Descrição da fêmea de Paracentronodus nevesi Barreira \& Sakakibara (Hemiptera, Membracidae). Um exemplar fêmea de Paracentronodus nevesi Barreira \& Sakakibara, 2001, de São José dos Cordeiros, região de semi-árido (Caatinga), do Estado da Paraíba, é descrito e ilustrado. Até o presente, apenas o macho era conhecido.

PALAVRAS-CHAVE. Caatinga; Centronodinae; Homoptera; taxonomia.

O gênero Paracentronodus foi proposto por Sakakibara (1971) para abrigar duas espécies: P. elevatus Sakakibara, 1971 e P. truncatus Sakakibara, 1971, a primeira (espécie-tipo) de Santa Catarina e, a segunda, de Minas Gerais. Posteriormente, Barreira \& Sakakibara (2001) transferiram Hemiptycha viridistriga Walker, 1858 para o gênero e acrescentaram mais sete espécies, entre as quais $P$. nevesi, de Caruaru, Pernambuco, descrita a partir de um único exemplar macho.

Neste trabalho, descreve-se a fêmea de $P$. nevesi coletada em São José dos Cordeiros, uma região de semi-árido (Caatinga), município do Estado da Paraíba.

\section{Paracentronodus nevesi Barreira \& Sakakibara} (Fig. 1)

Paracentronodus nevesi Barreira \& Sakakibara, 2001: 263.

Medidas (mm). Fêmea. Comprimento do corpo 6,26; comprimento do pronoto 4,28; altura do pronoto 3,72 ; comprimento das tégminas 5,70; largura da cabeça 2,38; altura da cabeça 0,95; distância entre os ângulos umerais 2,45.

Coloração. Cabeça, pronoto, tórax e abdome, castanhoacinzentados com discretas manchas amareladas; tégminas translúcidas nos dois terços apicais, com manchas castanhas no centro e às proximidades do ápice; asas posteriores translúcidas; coxas e trocanteres amarelados, fêmures castanho-acinzentados com manchas amareladas na base aumentando gradativamente de tamanho do fêmur I para o fêmur III; tíbias castanho-acinzentadas com manchas amarelas; perna III com tarsômeros basais amarelados.

Corpo recoberto com discreta pilosidade. Cabeça subretangular, duas vezes mais larga que longa; ligeiramente intumescida entre os ocelos; estes proeminentes e mais próximos dos olhos que entre si; pós-clípeo pequeno e subtriangular; lóbulos supra-antenais foliáceos. Pronoto sinuoso, distintamente mais elevado no meio; fortemente pontuado e constrito junto à base do clavo, expondo parcialmente o escutelo; processo posterior triangular estreitando-se a após a constrição em direção ao ápice, este dorsalmente deprimido, com uma mancha amarelada; metopídio convexo; processos supra-umerais curtos e cônicos; carena mediana distinta; tégminas coriáceas no terço basal; venação irregular com veias distintas e proeminentes. Pernas simples, tíbia II ligeiramente foliácea; tíbia III com três fileiras distintas de espinhos. Abdome subtriangular com uma pequena tuberosidade no esterno III. Placa subgenital triangular.

Comentários. A fêmea é semelhante ao macho, tanto na sua forma geral como na coloração. O seu tamanho, entretanto, é um pouco menor. A procedência dos exemplares, até agora conhecida, é de localidades com limitações hídricas: Caruaru, Pernambuco e São José dos Cordeiros, Paraíba. 


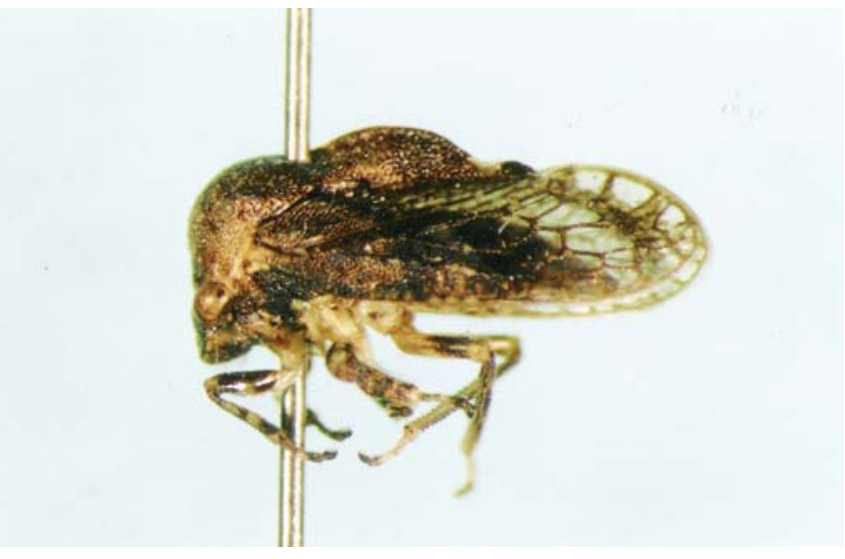

Fig. 1. Fêmea de Paracentronodus nevesi Barreira \& Sakakibara, 2001.
Material examinado. Brasil, Paraíba: 1 fêmea. "Faz[enda]. Almas, S[ão]. José / dos Cordeiros (PB) / (7\% 28' S 36 53' W) / 650m, Caatinga / 21-22/II/2004 Trs 04 / Rothéa, R. \& O. Souza" (DZUP - Coleção de Entomologia Pe. J. S. Moure, Departamento de Zoologia -UFPR, Curitiba-PR)

\section{REFERENNCIAS}

Barreira, R. L. \& Sakakibara, A. M. 2001. Espécies novas de Paracentronodus Sakakibara (Homoptera, Membracidae, Centrotinae). Revista Brasileira de Zoologia, Curitiba, 18: 255-267.

Sakakibara, A. M. 1971. Um gênero e duas espécies novas de Centrotinae (Homoptera, Membracidae). Revista Brasileira de Biologia, Rio de Janeiro 31: 467-470. 